\title{
Carboidratos dissolvidos do reservatório de Barra Bonita (Estado de São Paulo, Brasil) e sua relação com as algas fitoplanctônicas abundantes
}

\author{
Maria José Dellamano-Oliveira ${ }^{1,2}$, Vanessa Colombo-Corbi ${ }^{1}$ \& Armando Augusto Henriques Vieira
}

Biota Neotropica $v 7$ (n2) - http://www.biotaneotropica.org.br/v7n2/pt/abstract?article + bn00707022007

Recebido em 28/09/06

Versão reformulada recebida em 08/02/07

Publicado em 01/05/07

${ }^{1}$ Laboratório de Ficologia, Departamento de Botânica, Universidade Federal de São Carlos

Rodovia Washington Luís, Km 235, CP 676, CEP 13565-905, São Carlos, SP., Brasil.

${ }^{2}$ Autor para correspondência: Maria José Dellamano-Oliveira, e-mail: pdeol@ig.com.br,www.ufscar.br

\begin{abstract}
Dellamano-Oliveira, M.J., Colombo-Corbi, V. \& Vieira, A.A.H. Dissolved carbohydrates from Barra Bonita Reservoir (São Paulo State, Brazil) and its relationships with phytoplanktonic abundant algae. Biota Neotrop. May/Aug 2007 vol. 7, no. 2 http://www.biotaneotropica.org.br/v7n2/pt/abstract?article+bn00707022007. ISSN 1676-0603.

Dissolved carbohydrates and abundant algae of Barra Bonita Reservoir were studied monthly from June 2002 to January 2004 in six depths whose values vary depending on the seasons and the water level at a sampling site located $3 \mathrm{~km}$ upstream the Reservoir dam. Nearly $90 \%$ of the dissolved carbohydrates were constituted of polymeric hydrolysable carbohydrates (polysaccharides or oligosaccharides). Analysis of variance detected variability among concentrations of dissolved carbohydrates only in temporal scale $(\mathrm{p}<0.05)$, whereas in vertical axis the concentrations of these sugars were uniform $(\mathrm{p}>0.05)$. The monosaccharide composition of the sugars found in the reservoir was galactose, rhamnose, glucose e fucose. During the sampling period, higher concentrations of dissolved carbohydrates, mostly polymeric, occurred together with large phytoplanktonic blooms, predominantly cyanobacteria, which probably were the main source of extracellular polysaccharides in the system.
\end{abstract}

Keywords: phytoplankton, eutrophic reservoir, extracellular polysaccharide.

Resumo

Dellamano-Oliveira, M.J.; Colombo-Corbi, V. \& Vieira, A.A.H. Carboidratos dissolvidos do Reservatório de Barra Bonita (Estado de São Paulo, Brasil) e sua relação com as algas fitoplanctônicas abundantes. Biota Neotrop. May/Aug 2007 vol. 7, no. 2 http://www.biotaneotropica.org.br/v7n2/pt/abstract?article+bn00707022007. ISSN 1676-0603.

O estudo dos carboidratos dissolvidos e sua relação com as algas abundantes no reservatório de Barra Bonita, foi realizado em coletas mensais (junho de 2002 a janeiro de 2004), em seis profundidades na coluna d'água, cujos valores variaram dependendo da estação do ano e do nível do reservatório, num ponto fixo, localizado $3 \mathrm{~km}$ a montante da barragem. Aproximadamente $90 \%$ dos carboidratos dissolvidos neste reservatório foram constituídos por carboidratos poliméricos hidrolisáveis (polissacarídeos ou oligossacarídeos). A análise de variância detectou variabilidade entre as concentrações dos carboidratos dissolvidos apenas em escala temporal $(\mathrm{p}<0,05)$, sendo que no eixo vertical, as concentrações destes açúcares apresentaram-se homogêneas ( $p>0,05)$. A composição monossacarídica dos açúcares encontrados no reservatório foi galactose, ramnose, glicose e fucose. Na maioria dos meses amostrados, as concentrações de carboidratos dissolvidos, a maioria deles poliméricos, ocorreram concomitantemente ao registro de florescimentos das espécies abundantes, principalmente cianofíceas, que provavelmente foram as principais fontes de polissacarídeos extracelulares para o sistema.

Palavras-chave: fitoplâncton, reservatório eutrófico, polissacarídeos extracelulares. 


\section{Introdução}

Os carboidratos livres em corpos d'água naturais são constituídos por açúcares livres (monossacarídeos e dissacarídeos) e por carboidratos poliméricos hidrolisáveis, como os polissacarídeos e oligossacarídeos (Gremm 1997). Os açúcares livres e combinados constituem uma grande fração da maioria dos organismos e até $60 \%$ do peso seco de algumas algas (Mopper et al. 1992) e são liberados para o meio como resultado da excreção e morte das células.

Os polissacarídeos extracelulares excretados pelo fitoplâncton têm sido muito estudados, devido ao seu significado ecológico nos sistemas aquáticos (Zhou et al. 1998, Giroldo \& Vieira 2005), pois são comuns a esses organismos, podendo assim ser um excelente indicador da origem da matéria orgânica, particulada e dissolvida. Como constituintes das substâncias húmicas e fúlvicas podem levar a um melhor entendimento dos mecanismos da gênese da matéria orgânica complexa e pela sua susceptibilidade de complexar-se com metais traços, podem controlar a disponibilidade destes no meio aquático (Lombardi \& Vieira 2000, Freire-Nordi et al. 2005, Gouvêa et al. 2005, Nogueira et al. 2005). Desde que os polissacarídeos extracelulares podem ser usados como substrato por bactérias (Freire-Nordi \& Vieira 1998, Colombo et al. 2004), estes componentes podem realizar um importante papel na possível associação específica bactéria/alga (Grossart et al. 2003). Também são os principais componentes do carbono orgânico liberado pelas algas e são extremamente variáveis na sua composição monossacarídica e estereo-química. Outro importante papel dos polissacarídeos extracelulares é a formação de TEP (Transparent Exopolymer Particle), partículas mucilaginosas amorfas de tamanho variado que por sua vez, através de choques e agregação, podem formar os agregados gelatinosos lake snow (Trent et al. 1978), ambos de grande importância no fluxo de carbono através da cadeia trófica e para o sedimento.

Ao contrário dos numerosos estudos em laboratório com a liberação de carboidratos por monoculturas fitoplanctônicas (Myklestad 1995, Gouvêa et al. 2005, Giroldo \& Vieira 2005), apenas poucos estudos, principalmente relacionados com os florescimentos algáceos mostraram uma relação entre a composição do fitoplâncton e os níveis de carboidratos no ambiente natural (Ittekkot et al. 1981, Burney et al. 1981, Soares 1992). Outros trabalhos apenas forneceram a correlação de carboidratos com a biomassa total (Dhople \& Bhosle 1987, Senior $\&$ Chevolot 1991). O objetivo deste estudo foi relacionar a composição e a concentração dos carboidratos dissolvidos, especialmente os polissacarídeos, com as algas fitoplanctônicas abundantes do reservatório de Barra Bonita.

\section{Materiais e Métodos}

\section{1. Área de estudo}

O reservatório de Barra Bonita situa-se na Bacia do Médio Tietê Superior, na região central do Estado de São Paulo, entre os municípios de Igaraçu e Barra Bonita (22 $29^{\circ}$ a $22^{\circ} 44^{\prime} \mathrm{S}$ e $48^{\circ} 10^{\prime}$ a $48^{\circ} 34^{\prime} \mathrm{W}$ ), a uma altitude de $430 \mathrm{~m}$. Localizado numa das regiões mais populosas e desenvolvidas do Brasil, a barragem foi construída em 1963, constituindo-se parte do complexo de barragens situadas no rio Tietê, com uma área alagada de $324,84 \mathrm{~km}^{2}$, formada a partir do represamento dos rios Tietê e Piracicaba.

Este reservatório é um ecossistema polimítico, eutrófico, onde os altos níveis de nutrientes contribuem para o desenvolvimento de florações, principalmente de Microcystis aeruginosa Kützing (Cyanophyceae) durante o verão e de Aulacoseira granulata (Ehrenberg) Simonsen (Bacillariophyceae) no inverno (Dellamano-Oliveira 2006).

\section{Periodicidade e metodologia de amostragem}

As coletas foram realizadas mensalmente (junho de 2002 a janeiro de 2004) em um único ponto do reservatório, localizado $3 \mathrm{~km}$ a montante da barragem, em seis diferentes profundidades na coluna d'água, dependendo da estação do ano e do nível do reservatório.

As amostras foram coletadas nas seis profundidades citadas anteriormente, utilizando-se garrafa tipo Van Dorn.

\subsection{Coleta e análise do fitoplâncton}

As amostras coletadas foram colocadas em um frasco de volume conhecido $(100 \mathrm{ml})$, preservadas em lugol e mantidas no escuro até o momento da análise. A quantificação do fitoplâncton foi feita de acordo com o método de sedimentação em câmaras, descrito por Utermöhl (1958) e o tempo de sedimentação foi de, no mínimo 3 horas (Wetzel \& Likens 1991). O procedimento de contagem foi realizado por meio de transectos, utilizando-se um microscópio invertido da marca Zeiss, modelo Axiovert, com aumento máximo de 1000 vezes. Cada célula cenóbio, colônia ou filamento foram considerados como um indivíduo. Os indivíduos foram enumerados em campos aleatórios e a densidade dos organismos fitoplanctônicos foi calculada de acordo com APHA (1995). As espécies dominantes e abundantes foram determinadas segundo o critério descrito em Lobo \& Leighton (1986).

\subsection{Carboidratos dissolvidos (totais e poliméricos) $e$ monossacarídeos livres}

Para análise das concentrações dos carboidratos poliméricos (polissacarídeos) e dos monossacarídeos livres as amostras coletadas foram filtradas (aproximadamente $100 \mathrm{~mL}$ ) em filtros de fibra de vidro Whatman GF/F, com poro de $0,7 \mu \mathrm{m}$. Após a filtragem, as amostras foram concentradas 100 vezes em evaporador rotativo a $40{ }^{\circ} \mathrm{C}$ e subdivididas em duas sub-amostras. A primeira sub-amostra foi analisada diretamente em HPLC-PAD, sem hidrólise, para obtenção dos monossacarídeos livres e a outra foi hidrolisada para obtenção dos monossacarídeos totais (livres + poliméricos). Pela diferença (Poliméricos $=$ Totais - Livres), foram obtidas as concentrações de monossacarídeos que faziam parte dos polissacarídeos e oligossacarídeos. A metodologia utilizada está descrita em Wicks et al. (1991)

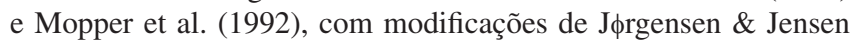
(1994) e Gremm \& Kaplan (1997).

O resumo da metodologia utilizada para identificação e quantificação por HPLC-PAD é apresentado a seguir: monossacarídeos livres e alguns dissacarídeos foram separados como ânions em uma solução alcalina (eluente, $18 \mathrm{mM} \mathrm{NaOH}$ ) através de HPLC. Para tanto foi utilizada uma coluna CarboPac PA-10, preenchida com resina polimérica não porosa com capacidade de troca aniônica de $100 \mu \mathrm{eq} \mathrm{e/ou} \mathrm{coluna}$ MA-1 $\left(\right.$ Dionex $\left.^{\circledR}\right)$ preenchida com resina "microporosa" polimérica

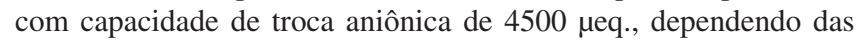
concentrações e dos açúcares presentes no local. Ambas as colunas têm a mesma sensibilidade e precisão, mas diferentes seletividades para os monossacarídeos. Os monossacarídeos e oligossacarídeos foram detectados em uma célula amperométrica equipada com um eletrodo de referência $\mathrm{Ag} / \mathrm{AgCl}$ e um eletrodo detetor de ouro, no qual, os carboidratos-ânions são oxidados. O eletrodo de ouro foi exposto a um pulso amperométrico positivo/negativo para a remoção dos produtos oxidados de maneira que o eletrodo detetor ficasse livre em curtíssimo intervalo de tempo para a detecção de outros ânions que iam chegando ao detetor, após separação na coluna CarboPac PA-10. Com o emprego de padrões apropriados pode-se identificar os monossacarídeos, dissacarídeos e até pequenos oligossacarídeos. Na impossibilidade de contar com padrões para determinados dissacarídeos e oligossacarídeos, estes foram hidrolisados juntamente com 
os polissacarídeos e seus monossacarídeos constituintes identificados e quantificados.

Devido às concentrações dos eluentes e da técnica utilizada nas análises em HPLC-PAD os açúcares manose e xilose foram co-eluídos.

\subsection{Análise estatística}

A fim de verificar diferenças espaciais (verticais) e temporais significativas entre as concentrações de carboidratos dissolvidos, foi aplicado o teste paramétrico de Tukey (Anova unidirecional), com nível de significância $(\alpha)$ de 0,05 ( $\mathrm{N}=228$, com réplica). Quando os resultados obtidos não apresentaram os pré-requisitos para a aplicação do teste paramétrico, como homogeneidade de variância, distribuição normal e aleatoriedade dos dados (Zar 1996) foi aplicado o teste não paramétrico de Kruskal-Wallis.

\section{Resultados}

\section{Carboidratos dissolvidos (Totais, Poliméricos e Livres)}

Cerca de $90 \%$ dos carboidratos dissolvidos no reservatório de Barra Bonita foram constituídos por carboidratos poliméricos hidrolisáveis (polissacarídeos ou oligossacarídeos). As concentrações dos carboidratos dissolvidos totais variaram de $0,22 \mathrm{mg} . \mathrm{L}^{-1} \mathrm{em}$ junho de 2003 a 13,41 mg.L $\mathrm{L}^{-1}$ em janeiro de 2004. A análise de variância (ANOVA unidirecional) detectou variabilidade entre as concentrações dos carboidratos dissolvidos (totais, poliméricos e monossacarídeos livres) apenas em escala temporal ( $p<0,05)$, visto que em geral, as maiores concentrações destes açúcares foram registradas durante as coletas realizadas no ano de 2002 . No eixo vertical, as concentrações apresentaram-se homogêneas ( $\mathrm{p}>0,05)$ (Tabela 1).

\section{Carboidratos poliméricos}

Em geral, as concentrações dos carboidratos poliméricos (polissacarídeos ou oligossacarídeos) acompanharam a dinâmica das espécies mais abundantes no reservatório, representadas por colônias de Microcystis aeruginosa e células livres de Microcystis sp. (Cyanophyceae), Aulacoseira granulata e Cyclotella menegheniana Kützing (Bacillariophyceae); Cryptomonas sp. (Cryptophyceae); Dictyopshaerium pulchellum Wood Smithson e Schroederia indica Philipose (Chlorophyceae) (Figura 1).

As maiores concentrações de monossacarídeos poliméricos foram registradas no ano de 2002, durante o período chuvoso. Os resultados obtidos pela ANOVA e pelo teste de Tukey mostraram a existência de variabilidade temporal (anual e sazonal) significativa $(\mathrm{p}<0,05)$ em relação às concentrações de monossacarídeos poliméricos (Tabela 2).

Os carboidratos poliméricos foram compostos principalmente por ramnose $(20,28 \%)$, glicose $(15,66 \%)$, galactose $(14,31 \%)$, arabinose $(13,9 \%)$ e fucose $(8,39 \%)$, que juntos compreenderam cerca de $72 \%$ da concentração total de monossacarídeos poliméricos no reservatório de Barra Bonita. As concentrações de manose e xilose foram obtidas conjuntamente e por este motivo aparecem em maior porcentagem.

As concentrações dos monossacarídeos poliméricos apresentaram-se mais elevadas durante as coletas realizadas nos meses mais quentes e de maior pluviosidade (outubro de 2002 a março de 2003), principalmente no ano de 2002, onde foram registrados grandes florescimentos de colônias de $M$. aeruginosa e de células livres de Microcystis sp. (Figura 2). Neste período também foram observadas grandes densidades de Cryptomonas sp. (Figura 3), de D. pulchellum e $S$. indica. Nos meses mais secos, A. granulata e C. menegheniana (Figura 4) foram as espécies mais abundantes,
Tabela 1. Concentração dos carboidratos dissolvidos totais (mg. $\left.\mathrm{L}^{-1}\right)$, poliméricos (mg.L $\left.{ }^{-1}\right)$ e de monossacarídeos livres $\left(\mathrm{mg} . \mathrm{L}^{-1}\right)$ registradas no reservatório de Barra Bonita, durante os meses de junho de 2002 a janeiro de 2004 (CDT: Carboidratos Dissolvidos Totais, C.P.: Carboidratos Poliméricos; C.L.: Carboidratos Livres; VT = variabilidade temporal; VE = variabilidade espacial).

Table 1. Concentration of total $\left(\mathrm{mg} . \mathrm{L}^{-1}\right)$, polymeric $\left(\mathrm{mg} . \mathrm{L}^{-1}\right)$ and free dissolved carbohydrates (mg. $\left.\mathrm{L}^{-1}\right)$ registered during the sampling period in Barra Bonita Reservoir (June 2002 to January 2004). (TDC: Total Dissolved Carbohydrates, P.C.: Polymeric Carbohydrates; F.C.: Free Carbohydrates; VT = temporal variability; $\mathrm{VE}=$ spatial variability).

\begin{tabular}{|c|c|c|c|}
\hline Coletas & C. D. T. & C.P. & C. L. \\
\hline jun/02 & 2,19 & 1,98 & 0,22 \\
\hline jul/02 & 0,68 & 0,65 & 0,03 \\
\hline ago/02 & 3,05 & 3,02 & 0,03 \\
\hline set/02 & 3,30 & 3,08 & 0,22 \\
\hline out/02 & 3,98 & 3,96 & 0,03 \\
\hline nov/02 & 2,67 & 2,67 & 0,01 \\
\hline $\mathrm{dez} / 02$ & 4,24 & 4,19 & 0,06 \\
\hline jan/03 & 2,24 & 2,22 & 0,03 \\
\hline fev/03 & 1,30 & 1,30 & 0,00 \\
\hline mar/03 & 3,61 & 3,60 & 0,02 \\
\hline $\mathrm{abr} / 03$ & 6,58 & 6,57 & 0,01 \\
\hline maio/03 & 0,82 & 0,81 & 0,02 \\
\hline jun/03 & 0,57 & 0,54 & 0,05 \\
\hline jul/03 & 0,22 & 0,21 & 0,01 \\
\hline ago/03 & 1,31 & 0,17 & 1,14 \\
\hline set/03 & 4,86 & 1,77 & 3,09 \\
\hline out/03 & 0,83 & 0,73 & 0,11 \\
\hline nov/03 & 1,40 & 1,39 & 0,01 \\
\hline $\mathrm{dez} / 03$ & 1,29 & 1,20 & 0,32 \\
\hline jan/04 & 13,41 & 10,67 & 2,74 \\
\hline Total & 58,55 & 50,72 & 8,13 \\
\hline Total (\%) & 100,00 & 86,62 & 13,89 \\
\hline V.T. & $\mathrm{p}<0,05$ & $\mathrm{p}<0,05$ & $\mathrm{p}<0,05$ \\
\hline V.E. & $\mathrm{p}>0,05$ & $\mathrm{p}>0,05$ & $\mathrm{p}>0,05$ \\
\hline
\end{tabular}

entretanto, as cianofíceas apresentaram-se em grandes densidades durante todo o período de estudo.

\section{Monossacarídeos livres}

A concentração de monossacarídeos livres registrada no reservatório foi de, aproximadamente, $10 \%$ em relação à concentração total de carboidratos dissolvidos. Os açúcares glicose, frutose e ribose juntos, representaram $97 \%$ da concentração total de monossacarídeos livres, enquanto que os demais monossacarídeos (fucose, ramnose, arabinose, galactose e manose/xilose) representaram, juntos, menos de $10 \%$ da concentração total de açúcares livres em Barra Bonita. Em geral as maiores concentrações de monossacarídeos livres foram registradas nos meses mais secos (junho e setembro de 2002, agosto e setembro de 2003), onde as diatomáceas (Bacillariophyceae) foram abundantes. No período chuvoso, onde em geral as cianofíceas, clorofíceas e criptofíceas apresentaram-se em maior densidade, foram registrados apenas dois picos de concentração de monossacarídeos livres, um em dezembro de 2003 e outro em janeiro de 2004 (Figura 5). 


\section{Discussão}

A comunidade fitoplanctônica do reservatório de Barra Bonita, considerado um ambiente eutrófico (Dellamano-Oliveira 2006), foi representada quantitativamente por poucas espécies (colônias de M. aeruginosa, células livres de Microcystis sp., Pseudanabaena mucicola (Huber-Pestalozzi \& Naumann) Bourrelly, Anabaena spiroides Klebahn, A. granulata, C. menegheniana, Cryptomonas sp.,
D. pulchellum e $S$. indica). As colônias de $M$. aeruginosa são formadas por quantidades variáveis de células imersas em uma matriz polissacarídica que, cedo ou tarde, é liberada na forma dissolvida ou coloidal para o meio circundante, quando da morte das colônias. Anabaena spiroides apresenta recobrindo seus filamentos uma enorme cápsula mucilaginosa, que ultrapassa em até quatro vezes o diâmetro das células, e que também é liberada para o meio após a morte das mesmas. Pseudanabaena mucicola é também uma grande produtora
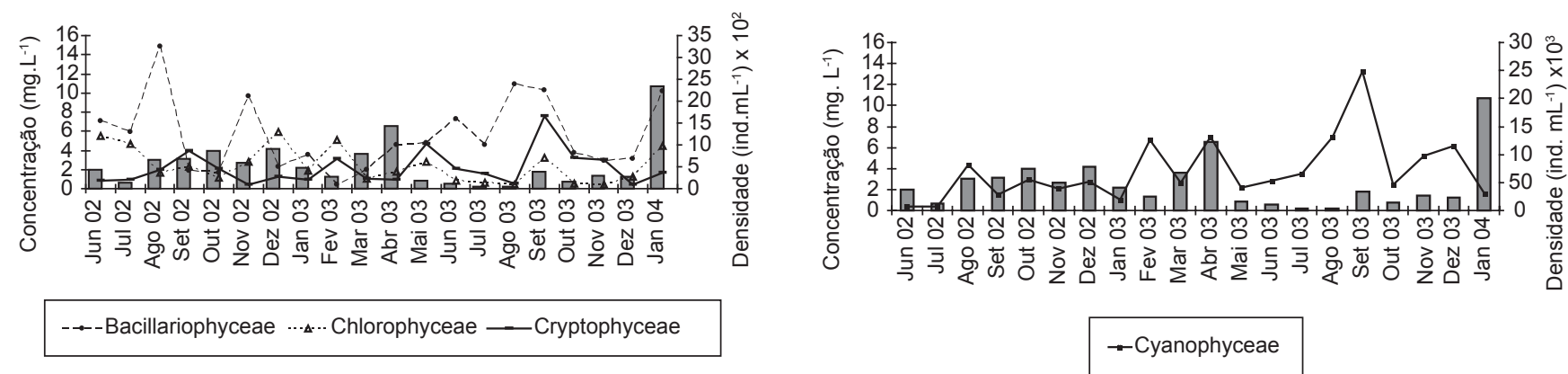

Figura 1. Concentração de carboidratos poliméricos $\left(\mathrm{mg} . \mathrm{L}^{-1}\right)$ e densidade (ind. $\left.\mathrm{mL}^{-1}\right)$ das classes fitoplanctônicas mais abundantes $(\mathrm{Cyanophyceae}$, Bacillariophyceae, Chlorophyceae e Cryptophyceae) registradas no reservatório de Barra Bonita durante os meses de junho de 2002 a janeiro de 2004 (As barras correspondem às concentrações de carboidratos poliméricos).

Figure 1. Concentration of polymeric carbohydrates $\left(\mathrm{mg} \cdot \mathrm{L}^{-1}\right)$ and density of abundant phytoplanktonic classes (Cyanophyceae, Bacillariophyceae, Chlorophyceae and Cryptophyceae) (ind. $\mathrm{mL}^{-1}$ ) registered during the sampling period in Barra Bonita Reservoir (June 2002 to January 2004) (Bars represent concentration of polymeric carbohydrates).

Tabela 2. Concentrações dos monossacarídeos poliméricos $\left(\mathrm{mg} \cdot \mathrm{L}^{-1}\right)$ registrados no reservatório de Barra Bonita, durante os meses de junho de 2002 a janeiro de 2004 (VT = variabilidade temporal; VE = variabilidade espacial).

Table 2. Concentration of polymeric monosaccharydes $\left(\mathrm{mg} . \mathrm{L}^{-1}\right)$ registered during the sampling period in Barra Bonita Reservoir (June 2002 to January 2004$)$ (VT = temporal variability; $\mathrm{VE}=$ spatial variability).

\begin{tabular}{|c|c|c|c|c|c|c|}
\hline Coletas & Ramnose & Galactose & Glicose & Fucose & Arabinose & Manose/Xilose \\
\hline jun/02 & 0,38 & 0,25 & 0,55 & 0,29 & 0,18 & 0,33 \\
\hline $\mathrm{jul} / 02$ & 0,11 & 0,09 & 0,12 & 0,08 & 0,05 & 0,18 \\
\hline ago/02 & 0,33 & 0,31 & 0,63 & 0,18 & 0,16 & 1,39 \\
\hline set/02 & 0,88 & 0,38 & 0,53 & 0,30 & 0,21 & 0,65 \\
\hline out/02 & 0,65 & 0,60 & 0,73 & 0,39 & 0,46 & 1,05 \\
\hline nov/02 & 0,54 & 0,36 & 0,44 & 0,26 & 0,38 & 0,66 \\
\hline $\mathrm{dez} / 02$ & 1,06 & 0,55 & 0,88 & 0,39 & 0,34 & 0,94 \\
\hline $\mathrm{jan} / 03$ & 0,51 & 0,27 & 0,53 & 0,09 & 0,21 & 0,47 \\
\hline fev/03 & 0,12 & 0,12 & 0,11 & 0,09 & 0,1 & 0,53 \\
\hline mar/03 & 0,61 & 0,36 & 1,20 & 0,14 & 0,19 & 0,91 \\
\hline $\mathrm{abr} / 03$ & 1,34 & 0,38 & 0,41 & 0,30 & 0,22 & 1,22 \\
\hline mai/03 & 0,00 & 0,00 & 0,73 & 0,00 & 0,00 & 0,02 \\
\hline jun/03 & 0,17 & 0,02 & 0,01 & 0,22 & 0,11 & 0,00 \\
\hline $\mathrm{jul} / 03$ & 0,02 & 0,01 & 0,06 & 0,04 & 0,02 & 0,02 \\
\hline ago/03 & 0,01 & 0,03 & 0,02 & 0,01 & 0,03 & 0,07 \\
\hline set/03 & 0,05 & 1,22 & 0,00 & 0,12 & 0,1 & 0,35 \\
\hline out/03 & 0,13 & 0,13 & 0,10 & 0,11 & 0,09 & 0,14 \\
\hline nov/03 & 0,23 & 0,21 & 0,45 & 0,10 & 0,13 & 0,31 \\
\hline $\mathrm{dez} / 03$ & 0,35 & 0,21 & 0,15 & 0,15 & 1,09 & 0,19 \\
\hline jan/04 & 2,82 & 1,74 & 0,30 & 1,00 & 4,07 & 3,11 \\
\hline$\%$ & 20,28 & 14,32 & 15,66 & 8,39 & 13,9 & 24,71 \\
\hline VT & $\mathrm{p}<0,05$ & $\mathrm{p}<0,05$ & $\mathrm{p}<0,05$ & $\mathrm{p}<0,05$ & $\mathrm{p}<0,05$ & $\mathrm{p}<0,05$ \\
\hline VE & $\mathrm{p}>0,05$ & $\mathrm{p}>0,05$ & $\mathrm{p}>0,05$ & $\mathrm{p}>0,05$ & $\mathrm{p}>0,05$ & $\mathrm{p}>0,05$ \\
\hline
\end{tabular}




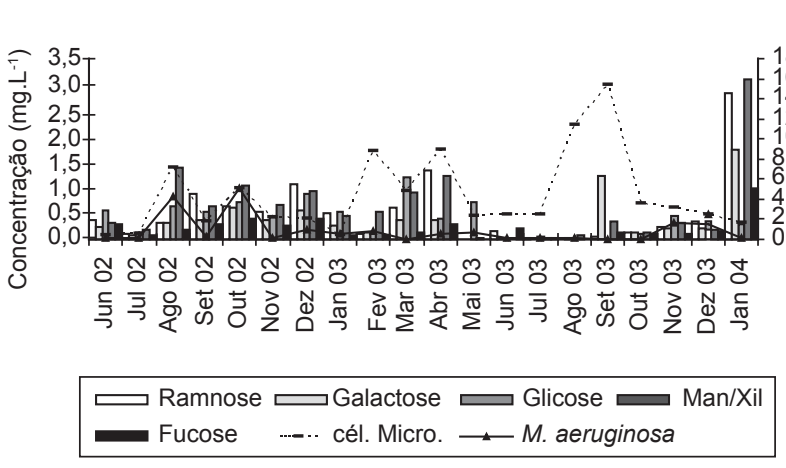

Figura 2. Concentração de monossacarídeos poliméricos $\left(\mathrm{mg} \cdot \mathrm{L}^{-1}\right)$ e densidade (ind. $\mathrm{mL}^{-1}$ ) de colônias de M. aeruginosa e células livres de Microcystis sp. registradas no reservatório de Barra Bonita durante os meses de junho de 2002 a janeiro de 2004.

Figure 2. Concentration of polymeric monosaccharydes (mg.L-1) and density (ind. $\mathrm{mL}^{-1}$ ) of colony of M. aeruginosa and free cells of Microcystis sp., registered during the sampling period in Barra Bonita Reservoir (June 2002 to January 2004).

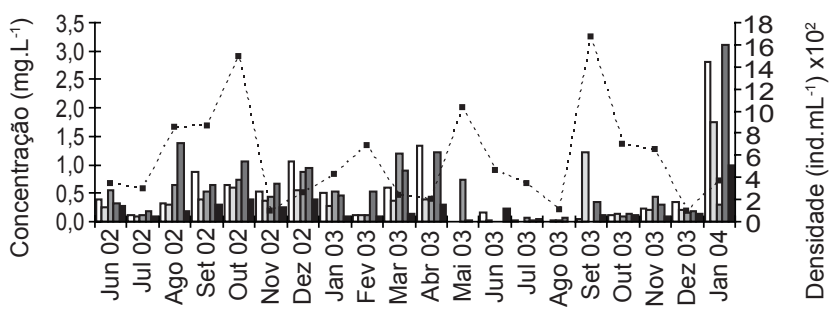

$$
\begin{aligned}
& \text { Ramnose } \sqsubset \text { Galactose } \text { Glicose } \\
& \text { Man/Xil Fucose ….... Cryptomonas sp. }
\end{aligned}
$$

Figura 3. Concentração de monossacarídeos poliméricos $\left(m g . L^{-1}\right)$ e densidade (ind. $\mathrm{mL}^{-1}$ ) de Cryptomonas sp., registradas no reservatório de Barra Bonita durante os meses de junho de 2002 a janeiro de 2004.

Figure 3. Concentration of polymeric monosaccharydes $\left(\mathrm{mg} . \mathrm{L}^{-1}\right)$ and density (ind. $\mathrm{mL}^{-1}$ ) of Cryptomonas sp., registered during the sampling period in Barra Bonita Reservoir (June 2002 to January 2004).

de polissacarídeos extracelulares que, quando em cultivos, tornam o meio de cultura gelatinoso. Devido ao fato destas três espécies estarem entre as maiores produtoras de biomassa no reservatório, seus polissacarídeos extracelulares representam a principal fonte de carboidratos poliméricos de origem "algal" no reservatório de Barra Bonita. A diatomácea Aulacoseira granulata, que ocorre também em grandes quantidades no reservatório, principalmente no inverno, é uma espécie que se caracteriza por não produzir grandes quantidades de polissacarídeos extracelulares (Vieira et al. 2006). Caracteristicamente, seu polissacarídeo extracelular fica aderido em baixas concentrações às paredes celulares formando finos filmes polissacarídicos ricos em ramnose e fucose. Apesar de Cryptomonas sp. ser uma das espécies mais frequientes do fitoplâncton do reservatório, a quantidade de sua biomassa não é tão representativa quanto a das cianofíceas. Porém, deve-se considerar que o grupo produz razoáveis quantidades de polissacarídeo extracelular altamente viscoso, rico em fucose e ácido glicurônico (Giroldo \& Vieira 2002), que é liberado para o meio na forma de colóides. Assim, na maioria dos meses amostrados, foi possível observar a relação entre as concentrações de carboidratos dissolvidos, a maioria deles poliméricos (polissacarídeos ou oligos-

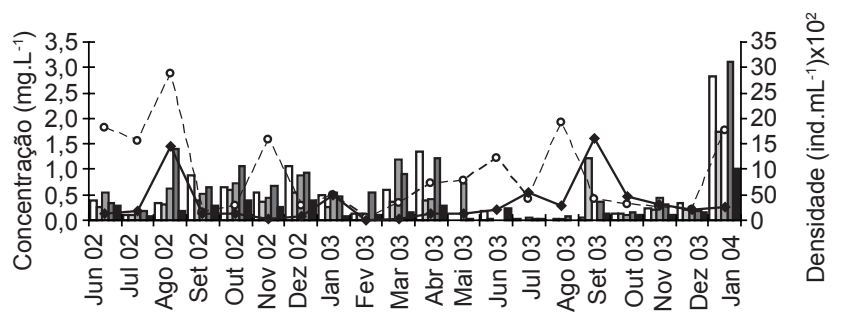

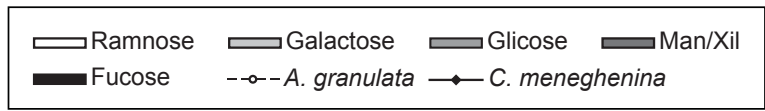

Figura 4. Concentração de monossacarídeos poliméricos $\left(\mathrm{mg} . \mathrm{L}^{-1}\right)$ e densidade (ind. $\mathrm{mL}^{-1}$ ) de A. granulata e C. menegheniana, registradas no reservatório de Barra Bonita durante os meses de junho de 2002 a janeiro de 2004.

Figure 4. Concentration of polymeric monosaccharydes $\left(\mathrm{mg} . \mathrm{L}^{-1}\right)$ and density (ind. $\mathrm{mL}^{-1}$ ) of A. granulata and C. menegheniana, registered during the sampling period in Barra Bonita Reservoir (June 2002 to January 2004).
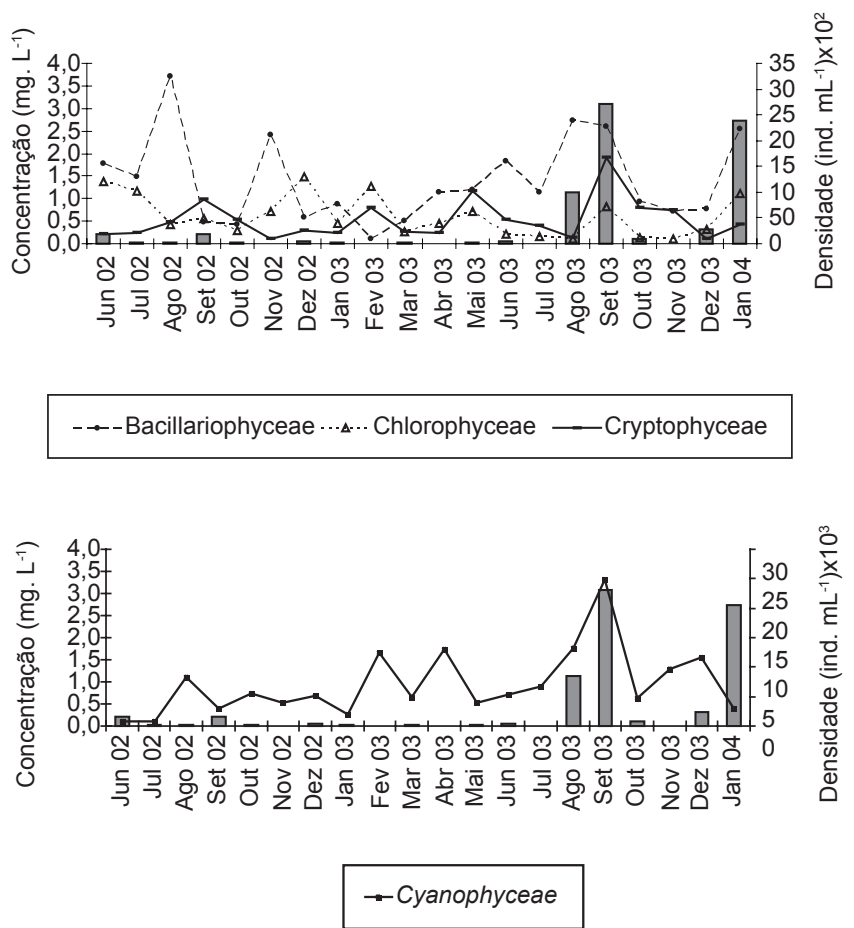

Figura 5. Concentração (mg. $\left.\mathrm{L}^{-1}\right)$ dos monossacarídeos livres e densidade (ind. $\mathrm{mL}^{-1}$ ) das classes fitoplanctônicas mais abundantes (Cyanophyceae, Bacillar-ophyceae, Chlorophyceae e Cryptophyceae) registradas no reservatório de Barra Bonita durante os meses de junho de 2002 a janeiro de 2004 (As barras correspondem às concentrações de monossacarídeos livres).

Figure 5. Concentration (mg. $\left.\mathrm{L}^{-1}\right)$ of free monosaccharydes and density (ind. $\mathrm{mL}^{-1}$ ) of phytoplanktonic abundant classes (Cyanophyceae, Bacillariophyceae, Chlorophyceae and Cryptophyceae) registered during the sampling period in Barra Bonita Reservoir (June 2002 to January 2004) (Bars represent concentration of free carbohydrates).

sacarídeos), e o registro das espécies abundantes, principalmente cianofíceas, consideradas grandes produtoras de polissacarídeos extracelulares (De Phillips \& Vicenzini 1998, Hoagland et al. 1993, Giroldo \& Vieira 2002, Tien et al. 2002, Shin et al. 2003). 
A relação entre a concentração de carboidratos dissolvidos totais e os florescimentos de cianofíceas também foi observada por Hayakawa (2004) e Satoh et al. (1986), entre Aphanothece clathrata (West \& West) e Microcystis aeruginosa, respectivamente, ambos para lagos do Japão. Em relação às diatomáceas, Faganeli et al. (1995) estudaram as variações sazonais dos carboidratos particulados no golfo de Trieste e encontraram uma correlação positiva entre carboidratos particulados e biomassa fitoplanctônica. Embora a correlação observada por estes autores refira-se a carboidratos particulados, os mesmos observaram a importância dos florescimentos, no caso representado pelas diatomáceas, como importante fonte de carboidratos, principalmente polissacarídeos, para o ambiente marinho.

A floração de algas planctônicas é uma característica comum a muitos ecossistemas aquáticos, inclusive para o reservatório de Barra Bonita e embora estes eventos permaneçam por poucas semanas ou dias, acredita-se que o estado fisiológico do fitoplâncton durante o florescimento seja determinante para a composição do açúcar (monossacarídeo) dos polissacarídeos liberados (Myklestad 1995, Meon \& Kirchman 2001, Giroldo \& Vieira 2002).

A composição monossacarídica dos carboidratos poliméricos (ramnose: 20,28\%, glicose: 15,65\%, galactose: $14,31 \%$, fucose: $8,32 \%$, arabinose: $13,9 \%$ e manose/xilose: $24,71 \%$ ) no reservatório foi semelhante às registradas em outros ambientes de água doce. Segundo Hayakawa (2004), os monossacarídeos poliméricos mais abundantes em lagos mesotróficos e eutróficos são a galactose e a glicose, pois estes açúcares são comuns em exopolímeros de cianofíceas e diatomáceas (Hoagland et al. 1993, De Philippis \& Vicenzini 1998), que foram as classes mais representativas quantitativamente neste estudo. Estes açúcares, juntamente com a ramnose, fucose, arabinose, manose e xilose podem ser todos provenientes da degradação do polissacarídeo liberado por populações fitoplanctônicas (Hedges et al. 1994, Hayakawa 2004).

A ramnose, a galactose e a glicose também foram os monossacarídeos mais abundantes registrados por Gouvêa et al. (2005) em culturas de $M$. aeruginosa isoladas do reservatório de Barra Bonita, enquanto que Colombo et al. (2004) registrou maior porcentagem de arabinose e glicose em amostras de A. spiroides, também isoladas deste reservatório. Outros estudos, como os de Gloaguen et al. (1995) e Nicolaus et al. (1999), também registraram elevadas concentrações destes açúcares em culturas de cianofíceas, como Anabaena sp., Anabaena tortulosa, Chroococcus minutus, Oscillatoria sp. e Phormidium sp.

As concentrações de manose e xilose foram as mais altas durante todo período de estudo, devido ao fato de terem sido obtidas conjuntamente. São açúcares comuns em polissacarídeos de microalgas, especialmente de populações de diatomáceas e criptofíceas, como mostrado nas Figuras 3 e 4 . Os estudos realizados por Giroldo et al. (2003), Gouvêa et al. (2005) e Giroldo \& Vieira (2005), também mostraram que estes monossacarídeos foram mais comuns em monoculturas de diatomáceas e criptofíceas isoladas do reservatório de Barra Bonita.

As principais fontes de frutose e de ribose provêm de material intracelular de células em decomposição, tanto de material autóctone quanto alóctone. Estes açúcares foram registrados em baixas concentrações durante o período de estudo, provavelmente por terem sido rapidamente consumidos pelas populações bacterianas do reservatório assim que liberados na coluna d'água. Segundo Wicks et al. (1991), a ribose pode indicar a influência do plâncton (bacté- ria, fitoplâncton e zooplâncton), já que faz parte da composição das moléculas de RNA.

A variabilidade temporal em relação às concentrações de monossacarídeos poliméricos ocorreu tanto em escala anual quanto sazonal, conforme comprovado pela ANOVA e pelo Teste de Tukey. Em geral, as maiores concentrações foram registradas no ano de 2002, durante o período chuvoso, enquanto que nos meses mais secos (junho e julho de 2002 e maio, junho e julho de 2003), nos quais a quantidade de chuvas foi pequena (Dellamano-Oliveira 2006) as concentrações destes açúcares foram menores. Nestes meses, as densidades das diatomáceas, principalmente $A$. granulata aumentaram, ocorrendo o inverso com as cianofíceas (colônias de $M$. aeruginosa e células livres de Microcystis sp.). Esses dados são corroborados por V. Colombo-Corbi (dados não publicados) que verificou que durante a estação seca foram registradas menores atividades enzimáticas sobre os carboidratos em comparação aos meses chuvosos.

Em relação aos monossacarídeos livres, a fonte mais importante destes açúcares em ambientes de água doce, aparentemente, é a degradação enzimática de carboidratos poliméricos, particulados e dissolvidos (Jørgensen \& Jensen, 1994). Assim, espera-se que após a produção de uma grande quantidade de carboidratos poliméricos algais, extracelulares, estruturais ou de reserva, ocorra aumento da concentração dos monossacarídeos livres que, no entanto, por serem de fácil absorção pelas bactérias apresentam-se sempre em baixas concentrações na maioria dos corpos d'água estudados (Ittekot et al. 1981, Hayakawa 2004).

Soares (1992) em seu estudo na Represa do Broa (SP), considerado um ambiente eutrófico, encontrou concentrações de monossacarídeos poliméricos e livres próximas às registradas neste estudo. Segundo este autor, as concentrações dos diferentes monossacarídeos ao longo do período de coleta, trouxeram indícios de que a comunidade fitoplanctônica foi o principal contribuinte para a concentração de carboidratos dissolvidos na represa.

Visto que os carboidratos, especialmente os polissacarídeos, muitas vezes compreendem de 80 a $90 \%$ da liberação extracelular total e que sua composição e concentração variam com o estado nutricional do ambiente, com o estado fisiológico do fitoplâncton (Myklestad 1995) e com a composição taxonômica da comunidade fitoplanctônica e dominância de determinadas espécies (Soares 1992, Shin et al. 2003, Hayakawa 2004), consideramos que as algas que mais contribuíram para a concentração total de carboidratos poliméricos no reservatório foram as cianofíceas (colônias de M. aeruginosa e células livres de Microcystis sp.), consideradas grandes produtoras de polissacarídeos extracelulares e cujos florescimentos foram registrados na maioria dos meses estudados. Além disso, o aumento da eutrofização, fato que vem ocorrendo no reservatório de Barra Bonita nos últimos anos (Calijuri et al. 2001, 2002, M. J. Dellamano-Oliveira et al., dados não publicados), tende a aumentar a quantidade de cianofíceas como Anabaena sp. e Microcystis sp., aumentando assim, a quantidade de polissacarídeos dissolvidos no reservatório como observado neste estudo. No entanto, não se pode descartar também o efeito das bactérias como fonte de carboidratos poliméricos. De fato, uma grande população bacteriana como a que ocorre em Barra Bonita (Fatibello 2005) tem ação dupla no que diz respeito a aspectos qualitativos e quantitativos dos carboidratos: degradar uma grande quantidade de carboidrato polimérico a monossacarídeos livres e, também, produzir grandes quantidades de seus próprios polissacarídeos extracelulares. 


\section{Agradecimentos}

À FAPESP, pelo auxílio financeiro, processos número 02/02517-6, 02/04117-5 e 99/07766-0 e ao CNPQ, processo número 352261/1996-0.

\section{Referências Bibliográficas}

APHA (AMERICAN PUBLIC HEALTH ASSOCIATION). 1995. Standard Methods for the Examination of water and wastewater, $16^{\text {th }}$ edn. APHA, Washington, American Water Works Association, 1268p.

BURNEY, C. M., DAVIS, P. G., JOHNSON, M., SIEBURTH, MCN. J. 1981. Dependence of dissolved carbohydrate concentrations upon small scale nanoplankton and bacterioplankton distributions in the western Saragasso Sea. Mar. Biol,. 65:289-296.

CALIJURI, M. C. \& DOS SANTOS, A. C. A. 2001. Temporal variations in phytoplankton primary production in a tropical reservoir (Barra Bonita, SP - Brazil). Hydrobiologia., 445:11-26.

CALIJURI M. C., DOS SANTOS, A. C. A., JATI, S. 2002. Temporal changes in the phytoplankton community structure in a tropical and eutrophic reservoir (Barra Bonita, SP - Brasil) J. Plankton Res., 24(7):617-634

COLOMBO, V., VIEIRA, A. A. H., MORAES, G. 2004. Activity of gliycosidases from freshwater heterotrophic microorganisms on the degradation of extracellular polysaccharide produced by Anabaena spiroides (Cyanobacteria). Braz. J. Microbiol., 35:110-116.

DELLAMANO-OLIVEIRA, M. J. 2006. Comunidade fitoplanctônica do reservatório de Barra Bonita e sua relação com a composição e concentração de polissacarídeos extracelulares e agregados gelatinosos. Tese de Doutorado, Universidade Federal de São Carlos, São Carlos, SP, 99p.

DE PHILIPPS, R \& VICENZINI, M. 1998. Exocelullar polyssacharides from cyanobacteria and their possible applications. FEMS, Microbiol. Review, 22:151-175.

DHOPLE, V. M. \& BHOSLE, N. B. 1987. Dissolved Carbohydrate in the Central Arabian Sea. Indian J. Mar. Science, 16:43-45.

FAGANELI, J., KOCVAC, N., LESKOVSEK, H, PEZDIC, J. 1995. Sources and fluxes of particulate organic matter in shallow coastal waters characterized by summer macroaggregate formation. Biogeochemistry, 29: 71-88.

FATIBELLO, S. H. S. 2005. Estudos sobre a ocorrência e caracterização das partículas de exopolímeros transparentes (TEP) no reservatório de Barra Bonita e sua colonização por bactérias. Tese de Doutorado, Universidade Federal de São Carlos, São Carlos, SP, 129p.

FREIRE-NORDI, C. S. \& VIEIRA, A. A. H. 1998. Degradability of polyssacharides compounds excreted by Ankistrodesmus densus Kors. (Chlorophyceae) in cultures of natural bacterial communities. Verh. Internat. Verein. Limnol., 26:1685-1688.

FREIRE-NORDI, C. S., VIEIRA, A. A. H., NASCIMENTO, O. R. 2005. The metal binding capacity of Anabaena spiroides extracellular polysaccharide: an EPR study. Proc. Biochemistry, 40:2215-2224.

GIROLDO, D. \& VIEIRA, A. A. H. 2002. An extracellular sulfated fucose rich polysaccharide produced by a tropical strain of Cryptomonas obovata (Cryptophyceae) J. Appl. Phycol., 14:185-191.

GIROLDO, D. \& VIEIRA, A. A. H. 2005. Polymeric and free sugars released by three phytoplanktonic species from a freshwater tropical eutrophic reservoir. J. Plankton Res., 27(7):695-705.

GIROLDO, D., VIEIRA, A. A. H., PAULSEN, B. S. 2003. Relative increase of deoxy sugars during microbial degradation of an extracellular polysaccharide released by a tropical freswater Thalasiosira sp (Bacillariophyceae). J. Phycol., 39:1109-1115.

GLOAGUEN, V., MORVAN, H., HOFFMAN, L. 1995. Released and capsular polysaccharides of Oscillatoriaceae (Cyanophyceae/Cyanobacteria). Arch Hydrobiol. Suppl 109:53-69.

GOUVÊA, S. P., VIEIRA, A.A.H., LOMBARDI, A. T. 2005. Copper and cadmium complexation by high molecular weight materials and of water from a eutrophic reservoir. Chemosphere, 60:1332-1339.
GREMM, T. J. \& KAPLAN, L.A. 1997. Dissolved carbohydrates in stream water determined by HPLC and pulsed amperometric detection. Limnol. Oceanogr. 42(2):385-393.

GROSSART, H. P., HIETANEN, S., PLOUG. H. 2003. Microbial dynamics on diatom aggregates in Øresund, Denmark. Mar. Ecol. Progr. Ser., 249:69-78.

HAYAKAWA, K. 2004. Seasonal variations and dynamics of dissolved carbohydrates in Lake Biwa. Org. Geochem., 35:169-179.

HEDGES, J. L., COWIE, G. L., RICHEY, J. E., QUAY, P. D., BENNER, R. 1994. Origins and processing of organic matter in the Amazon River as indicated by carbohydrates and amino acids. Limnol. Oceanogr., 39: 743-761.

HOAGLAND, K. D., ROSOWSKI, J. R., GRETZ, R., ROEMER, S. C. 1993. Diatom extracellular polymeric substances: function, fine structure, chemistry and physiology. J. Phycol., 29:537-566.

ITTEKOTT, V., BROCHMANN, U. H., MICHAELIS, W., DEGENS, E. T. 1981. Dissolved free and combined carbohydrates during a phytoplankton bloom in the Northern (North-Sea). Mar. Ecol. Prog. Ser., 4:299-305.

J $\phi$ RGENSEN, N. O G. \& JENSEN, R. E. 1994. Microbial fluxes of free monosacharides and total carbohydrates in freshwater determined by PAD-HPLC. FEMS Microbiol. Ecol., 14:79-94.

LOBO, E. \& LEIGHTON, G. 1986. Estruturas de las fitocenosis planctónicos de los sistemas de desembocaduras de rios y esteros de la zona central de Chile. Rev. Biol. Mar., 22 (1):143-170.

LOMBARDI, A.T. \& VIEIRA, A. A. H. 2000. Copper complexation by Cyanophyta and Chlorophyta exudates. Phycologia, 39:118-125.

MEON, B. \& KIRCHMAN, D. L. 2001. Dynamics and molecular composition of dissolved organic material during experimental phytoplankton blooms. Mar. Chem. 75:185-199.

MOPPER, K., SCHULTZ, C. A., CHEVOLOT, L., REVUELTA, R., DAWSON, R. 1992. Determination of sugar in unconcentrated seawater and other waters by liquid chromatography pulse amperometric detection. Environ. Science Technol., 26:133-138.

MYKLESTAD, S. M. 1995. Release of extracellular products by phytoplankton with special emphasis on polyssacharides. Science Total Environ., 165:155-164.

NICOLAUS, B., PANICO, A., LAMA, L., ROMANO, I., MANCA, M. C., DE GIULIO, A., GAMBACORTA, A. 1999. Chemical composition and production of exopolysacharides from representative members of heterocystous and non-heterocystous cyanobacteria. Phytochemistry, 52:639-647.

NOGUEIRA, P.F.M., MELÃO, M.G.G., LOMBARDI, A.T., VIEIRA, A.A.H. 2005. The effects of Anabaena spiroides (Cyanophyceae) exopolysaccharide on copper toxicity to Symocephalus serrulatus (Cladocera, Daphnidae). Fresh. Biol. 50:1560-1567.

SATOH, Y., HAYASHI, H., NAKAMOTO,N., OKINO, T. 1986. Regulating factors of the concentration of dissolved carbohydrates in a central water column of lake Suwa, Japan. Arch. Hydrobiol., 105(3): 299-319.

SENIOR, W. \& CHEVOLOT, L. 1991. Studies of dissolved carbohydrates (or carbohydrate-like substances) in a estuarine environment. Mar. Chem., 32:19-35.

SHIN, K. H., HAMA, T., HANDA, N. 2003. Effect of nutrient conditions on the copmposition of photosynthetic products in the East China Sea and surrounding waters. Deep-Sea Res. Part 2, Top. Stud. Oceanogr, 50:389-401.

SOARES, F. S. 1992. Estudo dos carboidratos dissolvidos livres e combinados na Represa do Broa (SP) e sua relação com a comunidade fitoplanctônica. Tese de Doutorado, Universidade Federal de São Carlos, São Carlos, SP, 127p.

TIEN, C. J., KRIVTSOV, V., LEVADO, E., SIGEE, D. C., WHITE, K. N. 2002. Occurrence of cell-associated mucilage and soluble extracellular polisaccharides in Rostherne Mere and their possible significance. Hydrobiologia, 485(1-3):245-252. 
TRENT, J. D., SHANKS, A. L., SILVER, M. W. 1978. In situ and laboratory measurements on macroscopic aggregates in Monterey Bay, California. Limnol. Oceanogr., 23:626-635.

UTERMÖHL, H. 1958. Zur Vervolkomnung der quantitativen phytoplankton: methodic. Inter. Verein. Theor. Ang. Limnol. Mitteil., 9:1-38.

VIEIRA, A. H., GIROLDO, D., ORTOLANO, P. I. 2006. Aggregate formation in axenic and microbial co-inoculated batch cultures of Aulacoseira granulata (Bacillariophyceae). Acta Limnol. Bras., 18(1):1-7.

WETZEL, R. G. \& LIKENS, G. E. 1991. Limnological Analysis. Springer - Verlag, New York, 391 p.
WICKS, R. J., MORAN, M. A., PITTMAN, L. J., HODSON, R. E. 1991 Carbohydrate signatures of aquatic macrophytes and their dissolved degradation products as determined by sensitive high-performance ion chromatography method. Appl. Environ. Microbiol. 57:3135-3143.

ZAR, J. H. 1996. Biostatistical analysis, $3^{\text {rd }}$ Ed., New Jersey: Prentice-Hall, $662 \mathrm{p}$.

ZHOU J, MOPPER, K, PASSOW, U. 1998. The role of surface active carbohydrates in formation of transparent exopolymer particles by bubble adsorption of seawater. Limnol. Oceanogr., 43:1860-1871. 